\title{
High dielectric constant nickel-doped titanium oxide films prepared by liquid-phase deposition
}

\author{
Ming-Kwei Lee $\cdot$ Chih-Feng Yen $\cdot$ Cho-Han Fan
}

Received: 19 November 2013/Accepted: 11 March 2014/Published online: 25 March 2014

(C) The Author(s) 2014. This article is published with open access at Springerlink.com

\begin{abstract}
The electrical characteristics of nickel-doped titanium oxide films prepared by liquid-phase deposition on p-type (100) silicon substrate were investigated. The aqueous solutions of ammonium hexafluorotitanate and boric acid were used as precursors for the growth of titanium oxide films and the dielectric constant is 29. The dielectric constant can be improved to 94 by nickel doping at the thermal annealing at $700{ }^{\circ} \mathrm{C}$ in nitrous oxide.
\end{abstract}

\section{Introduction}

Titanium oxide $\left(\mathrm{TiO}_{2}\right)$ has the properties of high refractive index, excellent transmittance in the visible and nearinfrared bands, and high electrical and chemical stability. It has been applied extensively to optoelectronic devices such as high-temperature optical filters, antireflection coatings, solar energy converters, and optical waveguides [1-3]. $\mathrm{TiO}_{2}$ can also be used as the dielectric material of the storage capacitor in dynamic random access memory (DRAM) and high-k gate dielectric of MOSFET because of its high dielectric constant [4, 5].

There are many methods for the growth of $\mathrm{TiO}_{2}$ film, such as sol-gel, magnetron sputtering, metal organic chemical

\section{M.-K. Lee}

Department of Electronic Engineering, Chung Yuan Christian University, Chung Li 32023, Taiwan, Republic of China

\section{C.-F. Yen $(\bowtie)$}

Department of Materials Science and Engineering, MingDao University, Chang Hua 52345, Taiwan, Republic of China e-mail: cfyen@mdu.edu.tw

\section{C.-H. Fan}

Department of Electrical Engineering, National Sun Yat-sen University, Kaohsiung 80424, Taiwan, Republic of China vapor deposition, liquid-phase deposition (LPD), and, etc. $[6,7]$. Liquid-phase deposition has many advantages such as high uniformity, good selectivity, mass production capability, conformal growth and low cost [8]. The structure of as-deposited $\mathrm{LPD}-\mathrm{TiO}_{2}$ is amorphous prepared at the near room temperature, but its dielectric constant is as low as about 4.7 [9]. The dielectric constant of $\mathrm{LPD}-\mathrm{TiO}_{2}$ can be much improved by high-temperature thermal annealing from the formation of anatase and rutile phases. Usually, the anatase phase of $\mathrm{TiO}_{2}$ will be formed in the temperature range of $400-800{ }^{\circ} \mathrm{C}$ and transformed into higher dielectric constant rutile phase at the temperature higher than $900{ }^{\circ} \mathrm{C}$ [10]. For $\mathrm{LPD}^{-\mathrm{TiO}_{2}}$, the dielectric constant of anatase phase is 29.5 at the thermal annealing of $450{ }^{\circ} \mathrm{C}$ [11]. The rutile phase $\mathrm{LPD}-\mathrm{TiO}_{2}$ is formed at the thermal annealing of $900{ }^{\circ} \mathrm{C}$ in this study. Such a high thermal annealing temperature will induce wafer warpage, doping redistribution, the inter-diffusion at interface and, etc.

Ni-doped $\mathrm{TiO}_{2}$ were wildly investigated currently [1216]. From a previous study [14], the annealing temperature for anatase-rutile transformation can be lowered by nickel (Ni) doping. Due to the local charge imbalance with the incorporation of $\mathrm{Ni}$ into $\mathrm{TiO}_{2}$, the generated oxygen vacancy can enhance atom migration to form the rutile phase. In this study, the crystallization and electrical characteristics of Ni-doped $\mathrm{LPD}-\mathrm{TiO}_{2}$ films grown on p-type (100) silicon substrate were investigated.

\section{Experimental procedure}

Boron-doped, p-type (100)-oriented silicon wafer with a resistivity of $15-25 \Omega-\mathrm{cm}$ was used as the substrate in this experiment. Ammonium hexafluorotitanate $\left(\left(\mathrm{NH}_{4}\right)_{2} \mathrm{TiF}_{6}\right)$ and boric acid $\left(\mathrm{H}_{3} \mathrm{BO}_{3}\right)$ aqueous solutions were used as 
precursors for the growth of $\mathrm{LPD}-\mathrm{TiO}_{2}$. For the growth of undoped $\mathrm{TiO}_{2}$ film, $20 \mathrm{ml}$ of $0.2 \mathrm{M}\left(\mathrm{NH}_{4}\right)_{2} \mathrm{TiF}_{6}$ and $20 \mathrm{ml}$ of $0.4 \mathrm{M} \mathrm{H}_{3} \mathrm{BO}_{3}$ were mixed as the growth solution. For the preparation of $0.2 \mathrm{M}\left(\mathrm{NH}_{4}\right)_{2} \mathrm{TiF}_{6}, 19.8 \mathrm{~g}$ of $\left(\mathrm{NH}_{4}\right)_{2} \mathrm{TiF}_{6}$ was added into $500 \mathrm{ml}$ deionized (DI) water and stirred steadily for $16 \mathrm{~h}$ at room temperature. For the preparation of $0.4 \mathrm{M}$ $\mathrm{H}_{3} \mathrm{BO}_{3}, 12.6 \mathrm{~g} \mathrm{H}_{3} \mathrm{BO}_{3}$ was mixed with $500 \mathrm{ml}$ DI water. The growth temperature was kept at $40{ }^{\circ} \mathrm{C}$. For Ni doping, $5 \mathrm{ml}$ saturated nickel chloride solution was added in the growth solution. The saturated nickel chloride solution was prepared by dissolving $118.8 \mathrm{~g}$ of $\mathrm{NiCl}_{2} \cdot 6 \mathrm{H}_{2} \mathrm{O}$ powder into $500 \mathrm{ml}$ DI water at room temperature. There is a high concentration of oxygen vacancy in as-grown $\mathrm{LPD}-\mathrm{TiO}_{2}$ film. Oxygen vacancy is the typical defect in $\mathrm{LPD}^{-\mathrm{TiO}_{2}}$ film [17]. Moreover, $\mathrm{LPD}-\mathrm{TiO}_{2}$ has more concentration oxygen vacancy than that by other deposition methods (sol-gel, magnetron sputtering and metal organic chemical vapor deposition) due to high concentration of water molecules examined by FTIR in $\mathrm{LPD}-\mathrm{TiO}_{2}$ film [9]. The oxygen vacancy can be removed efficiently by oxygen atom provided in $\mathrm{N}_{2} \mathrm{O}$ thermal annealing [18]. For the formation of anatase and rutile phases and reduction of oxygen vacancy of as-deposited undoped and doped $\mathrm{LPD}^{-\mathrm{TiO}_{2}}$ films, $\mathrm{N}_{2} \mathrm{O}$ was used as the treatment ambient in thermal annealing.

Scanning electron microscope (SEM) was used to measure the film thickness. X-ray was used to examine the crystalline structure. Chemical bonding was analyzed with X-ray photoemission spectroscopy (XPS). The capacitance-voltage characteristics were measured with Agilent E4280A meter at the frequency of $1 \mathrm{MHz}$ with 30-mV signal amplitude.

\section{Results and discussion}

Smooth undoped and Ni-doped $\mathrm{LPD}-\mathrm{TiO}_{2}$ films grown on $\mathrm{Si}$ were obtained. The thicknesses of undoped and $\mathrm{Ni}$ doped $\mathrm{LPD}^{-\mathrm{TiO}_{2}}$ films as a linear function of the deposition time at the deposition temperature of $40{ }^{\circ} \mathrm{C}$ are shown in Fig. 1. The growth rates are 42.7 and $40.1 \mathrm{~nm} / \mathrm{h}$, respectively. The thicknesses of $\mathrm{TiO}_{2}$ films were measured by SEM. Therefore, a quite low measurement error for the growth rate of about $5 \%$ can be obtained. The repeatability is quite high and the run to run error is about $10 \%$. The slightly lower growth rate with $\mathrm{Ni}$ doping could be from the hindrance of $\mathrm{Cl}_{2}$ molecules. The XPS of thermally annealed Ni-doped $\mathrm{LPD}-\mathrm{TiO}_{2}$ film at $700{ }^{\circ} \mathrm{C}$ is shown in Fig. 2. Carbon is from the surface contamination. The weak Ni peaks shown in the inset indicate the successful $\mathrm{Ni}$ doping. The concentration is estimated to be about $300 \mathrm{ppm}$. Ni dopant concentration can be controlled by modulating the volume of saturated nickel chloride solution in the growth solution.

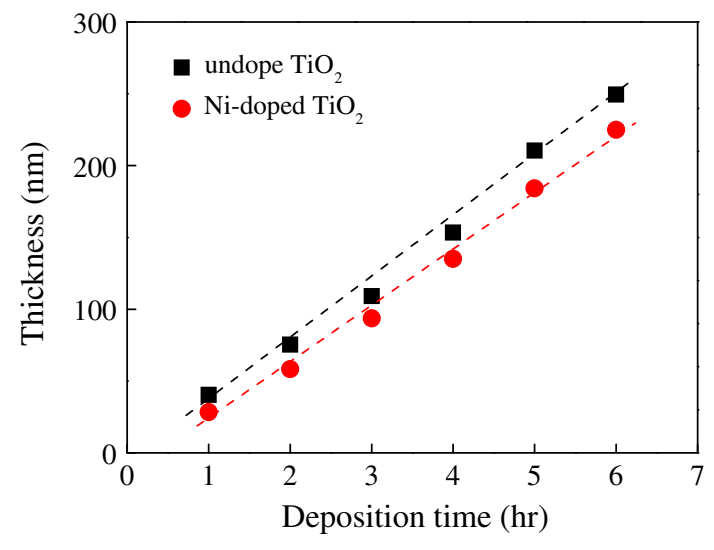

Fig. 1 Thickness of undoped and Ni-doped LPD-TiO $\mathrm{T}_{2}$ films as a linear function of the deposition time at the deposition temperature of $40{ }^{\circ} \mathrm{C}$

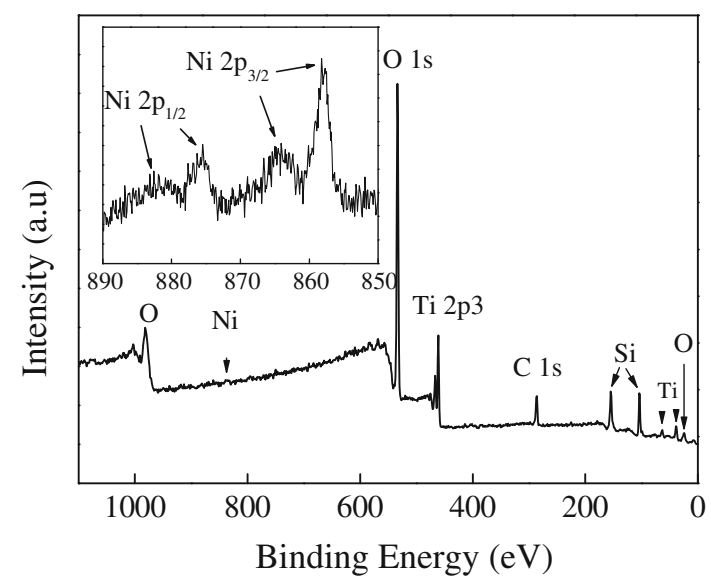

Fig. 2 X-ray photoelectron spectroscopy of annealed Ni-doped LPD$\mathrm{TiO}_{2}$

The X-ray diffraction spectra of as-deposited and annealed $\mathrm{Ni}$-doped $\mathrm{LPD}^{-\mathrm{TiO}_{2}}$ films in the range of $600-900{ }^{\circ} \mathrm{C}$ are shown in Fig. 3. The structure of asdeposited $\mathrm{TiO}_{2}$ is amorphous. The low signal-to-noise ratio indicates that $\mathrm{TiO}_{2}$ nanoparticles are contained in an amorphous matrix. The $\mathrm{TiO}_{2}$ anatase phase with the orientations of (101), (112) and (200) is observed at the annealing temperature of $600{ }^{\circ} \mathrm{C}$ and decreases with the annealing temperature [19]. The $\mathrm{TiO}_{2}$ rutile phase with the orientation of (002) is observed at the annealing temperature of as low as $700{ }^{\circ} \mathrm{C}$ from the generation of oxygen vacancy by the replacement of Ti by $\mathrm{Ni}[14,20]$. The intensity of rutile phase increases at $800{ }^{\circ} \mathrm{C}$ and then decreases slightly at $900{ }^{\circ} \mathrm{C}$, because of the high replacement of $\mathrm{Ti}$ by $\mathrm{Ni}$ and partial destruction of $\mathrm{Ti}-\mathrm{O}$ (bond length of $1.972 \AA$ [22]) rutile phase [23] by the shorter $\mathrm{Ni}-\mathrm{O}$ bond length of $1.77 \AA$ [21]. The anatase phase disappears at $900{ }^{\circ} \mathrm{C}$ from the complete transformation into the rutile phase. 


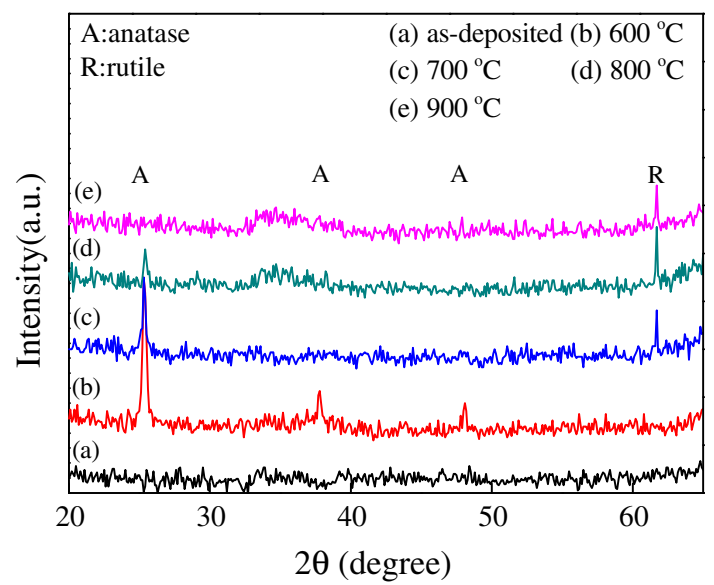

Fig. 3 XRD spectra of annealed Ni-doped $\mathrm{LPD}^{-\mathrm{TiO}_{2}}$ films in the range of $600-900{ }^{\circ} \mathrm{C}$

(a)

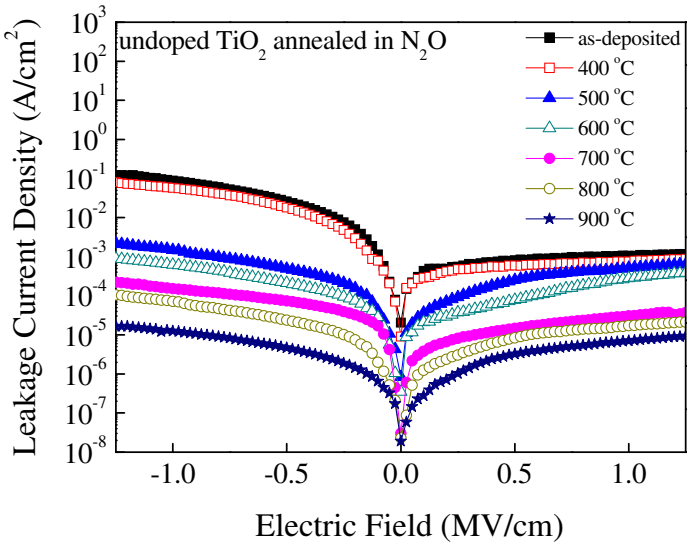

(b)

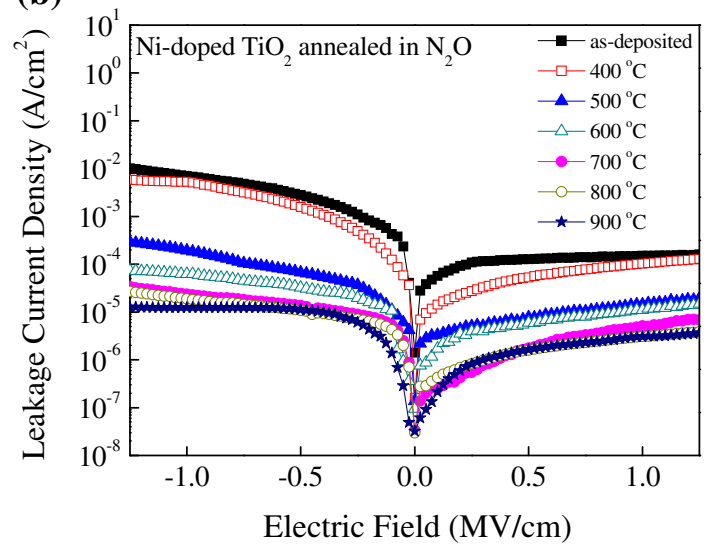

Fig. 4 a I-V characteristics of undoped LPD-TiO ${ }_{2}$ films as a function of annealing temperature. b I-V characteristics of Ni-doped $\mathrm{TiO}_{2}$ films as a function of the annealing temperature

The leakage current densities of as-deposited and annealed samples undoped $\mathrm{LPD}-\mathrm{TiO}_{2}$ films with a fixed thickness of $220 \mathrm{~nm}$ are shown in Fig. 4a. The high
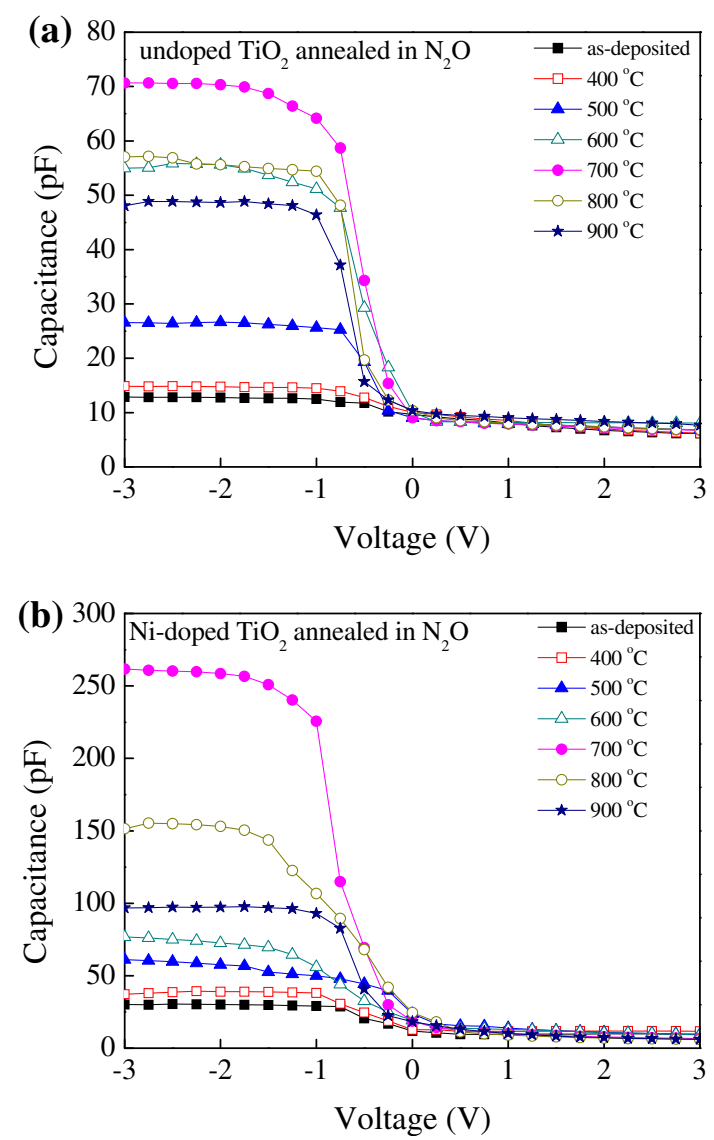

Fig. 5 a $\mathrm{C}-\mathrm{V}$ characteristics of undoped $\mathrm{LPD}-\mathrm{TiO}_{2}$ films as a function of annealing temperature. $\mathbf{b} \mathrm{C}-\mathrm{V}$ characteristics of Ni-doped $\mathrm{TiO}_{2}$ films on $\mathrm{Si}$ as a function of the annealing temperatures

leakage current density of as-deposited $\mathrm{LPD}-\mathrm{TiO}_{2}$ film is from oxygen vacancies. After $\mathrm{N}_{2} \mathrm{O}$ annealing, the leakage current density decreases with the annealing temperature from the decrease of oxygen vacancy. For the annealing temperature from 400 to $700{ }^{\circ} \mathrm{C}$, the leakage current densities are improved from $8.84 \times 10^{-4}$ and $7.65 \times 10^{-2}$ $\mathrm{A} / \mathrm{cm}^{2}$ to $3.69 \times 10^{-5}$ and $2.23 \times 10^{-4} \mathrm{~A} / \mathrm{cm}^{2}$ at \pm 1.25 $\mathrm{MV} / \mathrm{cm}$, respectively. The further decrease of leakage current density at the annealing temperature higher than $800{ }^{\circ} \mathrm{C}$ is due to the formation of $\mathrm{SiO}_{2}$ at the $\mathrm{TiO}_{2} / \mathrm{Si}$ interface [24], which is supported by the following $\mathrm{C}-\mathrm{V}$ characterization.

The I-V characteristics of Ni-doped $\mathrm{TiO}_{2}$ films as a function of the annealing temperature in $\mathrm{N}_{2} \mathrm{O}$ are shown in Fig. 4b. The leakage current density of as-deposited Nidoped film is lower than that of as-deposited undoped film. It is because the stoichiometry of $\mathrm{NiO}$ is usually metal deficient and the excess oxygen will compensate the oxygen vacancy of $\mathrm{TiO}_{2}$ [25]. The leakage currents are improved to $6.88 \times 10^{-6}$ and $3.39 \times 10^{-5} \mathrm{~A} / \mathrm{cm}^{2}$ at $\pm 1.25 \mathrm{MV} / \mathrm{cm}$ at the annealing temperature of $700{ }^{\circ} \mathrm{C}$. The leakage current is improved slightly for the annealing 
Table $1 k$ values of undoped and doped films as a function of annealing temperature

\begin{tabular}{lllllll}
\hline Annealing temperature $\left({ }^{\circ} \mathrm{C}\right)$ & 400 & 500 & 600 & 700 & 800 & 900 \\
Undoped films $k$ values & 6 & 11 & 23 & 29 & 23 & 20 \\
$\begin{array}{l}\text { Doped films } \\
k \text { values }\end{array}$ & 14 & 21 & 27 & 94 & 56 & 35 \\
\hline
\end{tabular}

temperature higher than $800{ }^{\circ} \mathrm{C}$ from the formation of $\mathrm{SiO}_{2}$ at the $\mathrm{TiO}_{2} / \mathrm{Si}$ interface.

The $\mathrm{C}-\mathrm{V}$ characteristics of undoped films as a function of annealing temperature were shown in Fig. 5a. The low accumulation capacitance of as-deposited $\mathrm{TiO}_{2}$ film is from its amorphous structure and high leakage current. The capacitance increases with the annealing temperature due to the reduction of water molecules and hence the leakage current. It decreases at the annealing temperature higher than $800{ }^{\circ} \mathrm{C}$ from the formation of $\mathrm{SiO}_{2}$ at interface. The $k$ values are $6,11,23,29,23$ and 20 from 400 to $900{ }^{\circ} \mathrm{C}$.

The $\mathrm{C}-\mathrm{V}$ characteristics of Ni-doped $\mathrm{TiO}_{2}$ films as a function of the annealing temperature are shown in Fig. 5b. The accumulation capacitance of as-deposited amorphous $\mathrm{TiO}_{2}$ film is larger than that of undoped one due to lower leakage current. The capacitance increases with the annealing temperature due to the reduction of oxygen vacancy. It decreases at the annealing temperature higher than $800{ }^{\circ} \mathrm{C}$ from the formation of $\mathrm{SiO}_{2}$ at the $\mathrm{TiO}_{2} / \mathrm{Si}$ interface. The $k$ values are 14, 21, 27, 94, 56 and 35 at from 400 to $900{ }^{\circ} \mathrm{C}$. From Fig. 3, the X-ray peak intensity of anatase phase is $600>700{ }^{\circ} \mathrm{C}$, but the peak intensity of rutile phase at $600{ }^{\circ} \mathrm{C}$ is negligible. Therefore, the $k$ value of Ni-doped $\mathrm{TiO}_{2}$ film annealed at $700{ }^{\circ} \mathrm{C}$ is larger than that at $600{ }^{\circ} \mathrm{C}$. The peak intensity of rutile phase is $800>700{ }^{\circ} \mathrm{C}$, but that of anatase phase is $800<700{ }^{\circ} \mathrm{C}$ at a relatively larger extent. Therefore, the $k$ value of Nidoped $\mathrm{TiO}_{2}$ film annealed at $700{ }^{\circ} \mathrm{C}$ is larger than that at $800{ }^{\circ} \mathrm{C}$. From above discussion, the $k$ value of Ni-doped $\mathrm{TiO}_{2}$ film has a maximum at the annealing temperature of $700{ }^{\circ} \mathrm{C}$.

To read more clearly, the $k$ values of undoped and doped films as a function of annealing temperature are listed in Table 1.

\section{Conclusions}

In conclusion, the electrical characteristics of nickel-doped titanium oxide films prepared by liquid-phase deposition on p-type (100) silicon substrate were improved from the decrease of oxygen vacancy by the excess oxygen compensation of $\mathrm{NiO}$. The dielectric constant of nickel-doped LPD-TiO ${ }_{2}$ film can be improved to 94 at thermal annealing temperature of as low as $700{ }^{\circ} \mathrm{C}$ in nitrous oxide. It is from that the rutile phase formation for Ni-doped $\mathrm{TiO}_{2}$ film is lower than that of undoped one from the oxygen vacancy generation by Ni doping.

Acknowledgments The authors would like to thank the National Science Council of Republic of China for their support under contract Nos. 98-2221-E110-073-MY3 and NSC101-3113-E-182-001-CC2.

Open Access This article is distributed under the terms of the Creative Commons Attribution License which permits any use, distribution, and reproduction in any medium, provided the original author(s) and the source are credited.

\section{References}

1. M.A. Butler, D.S. Ginley, J. Mater. Sci. 15, 1 (1980)

2. T. Carlson, G.L. Griffin, J. Phys. Chem. 90, 5896 (1986)

3. X.R. Wang, H. Masumoto, Y. Someno, T. Hirai, J. Jpn. Inst. Metals. 62, 1069 (1998)

4. K. Vydianathan, G. Nuesca, G. Peterson, E.T. Eisenbraun, A.E. Kaloyeros, J.J. Sullivan, B. Han, J. Mater. Res. 16, 1838 (2001)

5. J. Yan, D.C. Gilmer, S.A. Campbell, W.L. Gladfelter, R.G. Schmid, J. Vac. Sci. Technol. B. 14, 1706 (1996)

6. M.K. Lee, C.F. Yen, J.J. Huang, S.H. Lin, J. Electrochem. Soc. 153, 266 (2006)

7. M.K. Lee, J.J. Huang, C.M. Shih, C.C. Cheng, Jpn. J. Appl. Phys. 41, 4689 (2002)

8. T.J. Richardson, M.D. Rubin, J. Electrochem. Soc. 46, 2119 (2001)

9. M.K. Lee, B.H. Lei, Jpn. J. Appl. Phys. 39, L101 (2000)

10. J.G. Yu, H.G. Yu, B. Cheng, X.J. Zhao, J.C. Yu, W.K. Ho, J. Phys. Chem. B. 107, 13871 (2003)

11. M.K. Lee, H.C. Lee, C.M. Hsu, Mater. Sci. Semicond. Process. 10, 61 (2007)

12. K. Karthick, S. Kesavapandian, N. Victor Jaya, Appl. Surf. Sci. 256, 6829 (2010)

13. M. Dhayal, S.D. Sharma, C. Kant, K.K. Saini, S.C. Jain, Surf. Sci. 602, 1149 (2008)

14. K.S. Hwang, J.H. Jeong, J.H. Ahn, B.H. Kim, Ceram. Int. 32, 935 (2006)

15. V. Rodríguez-González, M.A. Ruiz-Gómez, L.M. Torres-Martínez, R. Gómez, Top. Catal. 54, 490 (2011)

16. S.D. Sharma, D. Singh, K.K. Saini, C. Kant, V. Sharma, S.C. Jain, C.P. Sharma, Appl. Catal. A 314, 40 (2006)

17. J. Strunk, W.C. Vining, A.T. Bell, J. Phys. Chem. C 113, 16937 (2010)

18. S.C. Sun, T.F. Chen, Tech. Dig. Int. Electron Devices Meet. 333 (1994)

19. J. Liqiang, S. Xiaojun, C. Weimin, X. Zili, D. Yaoguo, F. Honggang, J. Phys. Chem. Solids 64, 615 (2003)

20. N.H. Hong, J. Sakai, W. Prellier, J. Magn. Magn. Mater. 281, 347 (2004)

21. H. Peng, J. Li, S.S. Li, J.B. Xia, J. Phys. Chem. C 112, 13964 (2008)

22. G. Kleinle, J. Wintterlin, G. Ertl, R.J. Behm, F. Jona, W. Moritz, Surf. Sci. 225, 171 (1990)

23. Y. Wang, L. Zhang, J. Phys. Chem. C 113, 9210 (2009)

24. M. Kadoshima, M. Hiratani, Y. Shimamoto, K. Torii, H. Miki, S. Kimura, T. Nabatame, Thin Solid Films 424, 224 (2003)

25. P. Kofstad, Oxid. Met. 44, 3 (1995) 